\title{
OTR7 Gestão orientada para resultados e apuração dos custos da pesquisa clínica associada à assistência: uma avaliação da experiência do Ipec/Fiocruz
}

Marcelino José Jorge ${ }^{1}$, Cristina Monken Avellar ${ }^{1}$, Daniela de Souza Ferreira $^{1}$, Alexandre Monken Avellar ${ }^{1}$, Jaqueline Watanabe Oliveira ${ }^{1}$, Patrícia Santos Cavalheiro Silva ${ }^{1}$

${ }^{1}$ Fiocruz, Rio de Janeiro, RJ

Introdução: Com a adoção da gestão orientada para resultados na Fiocruz nos anos 90, os demonstrativos característicos do modelo de acompanhamento da execução orçamentária sob a ótica da gestão de processos foram complementados por estimativas das despesas por objetivos, desde então requeridas dos planos estratégicos submetidos ao Conselho Deliberativo da Fundação pelos Institutos (PA). Quanto ao Ipec, implantou as subestruturas de pesquisa clínica associada à assistência em 1999 e, em 2004, iniciou o Projeto de Avaliação e Acompanhamento - Indicadores de Gestão (PAA-IGs), devotado ao desenvolvimento de dois modelos: um, de levantamento, em nível de microcustos, das despesas inscritas nos orçamentos do lpec e da Administração Central da Fiocruz, e de apuração, pelo método de Custeio Baseado em Atividades, dos custos unitários efetivos das ações integradas de pesquisa clínica associada à assistência do Ipec (PAl); e, o segundo, de análise de eficiência destas ações no uso de recursos.

Objetivo: Caracterizar a variedade de tipos de atividades e serviços cujas estimativas de despesas foram apuradas pelo PAA-IGs a cada dois anos a partir de 2004 e compará-las com as estimativas constantes dos demonstrativos da execução orçamentária e das planilhas do PA.

Metodologia: A comparação da abrangência das despesas estimadas sobre os serviços monitorados no Ipec pelo PAA-IGs, pelo PA e pela execução orçamentária toma por base o estudo de caso da atividade de assistência do Ipec no ano 2009. Finalmente, esses três modelos de estimativa de despesas são comparados quanto à compatibilidade de cada um com as prescrições da literatura de gestão orientada para resultados.

Resultados: O PAA-IGs apura as despesas incorridas em diversos tipos de: exames (420); consultas médicas e de clínicas complementares (23); procedimentos médicos e de enfermagem (97); egressos de cursos (5); produção científica (4); PAI (13) e projetos em andamento (264). A preços de 2009, os valores das despesas estimadas pelo PAA-IGs é maior que o das despesas estimadas pela execução orçamentária e pelo PA. Das 9 prescrições de procedimentos 
de apuração de custos identificadas na literatura da gestão orientada para resultados, 6 são atendidas somente pelo PAA-IGs.

Conclusão: A análise empreendida permite evidenciar a variedade das informações levantadas pelo sistema de gerenciamento de custos PAA-IGs para o apoio à tomada de decisão, assim como caracterizar a compatibilidade do modelo com os princípios da gestão orientada para resultados, além de confirmar a hipótese de aferição das estimativas anteriores de apuração de custos da pesquisa clínica associada à assistência através dos procedimentos de levantamento de dados básicos e de cálculo adotados. Os resultados obtidos não podem ser generalizados, mas justificam a utilização do modelo PAAIGs em estudos de análise custo-efetividade dos esquemas de tratamento com tempo de seguimento finito e conhecido das organizações públicas multipropósito de saúde.

Palavras-Chave: Pesquisa Clínica, Avaliação, Microcusto 